\title{
ROLE OF CT IN THE EVALUATION OF ACUTE CHOLECYSTITIS
}

\author{
Murali Belman1, Mandapal Toka², Surekha Panditi ${ }^{3}$
}

${ }^{1}$ Associate Professor, Department of Radiology, Bhaskar Medical College and General Hospital, Yenkapally, Telangana, India. 2Professor, Department of Radiology, Bhaskar Medical College and General Hospital, Yenkapally, Telangana, India. 3Professor, Department of Radiology, Bhaskar Medical College and General Hospital, Yenkapally, Telangana, India. ABSTRACT

\section{BACKGROUND}

Acute cholecystitis is an acute inflammatory condition of the gall bladder. Cross-sectional imaging is critical in identifying the complications associated with acute cholecystitis. While ultrasound is still the first investigation for patients suspected of cholecystitis, acute cholecystitis and complications that emerge of it are better appreciated by CT. The sensitivity with which it can be evaluated is better with C.T.

\section{METHODS}

This is a prospective observational study done on 50 patients, on whom CT was performed, over a period of 14 months between March 2016 and May 2017.

\section{RESULTS}

50 patients with symptoms related to acute cholecystitis were evaluated by CT. The average age of the group was $60.7 \pm 1.76$ (range 31-80) with a sex distribution in the group being 21:29 (M: F). Right upper quadrant pain was the most common presenting complaint in $84.0 \%$ of cases. Fever (36.0\%), nausea (32\%), vomiting (30.0\%), dyspepsia (28.0\%), jaundice (22.0\%), vague abdominal discomfort (16.0\%), right upper quadrant mass $(16.0 \%)$, and abdominal distension $(2.0 \%)$ were the other presenting complaints. 42 of them $(84.0 \%)$ had calculi, $33(66.0 \%)$ patients show wall thickness of more than $4 \mathrm{~mm}$ and 32 (64.0\%) cases showed grossly distended GB. Pericholecystic fluid/oedema was seen in 32 (64.0\%) cases and 42 (84.0\%) cases show the presence of pericholecystic fat stranding. 21 cases (42.0\%) showed enhancement of the adjacent liver parenchyma.

\section{CONCLUSIONS}

CT is a reliable imaging modality for diagnosing of acute cholecystitis and its associated complications in emergency department. Cholelithiasis, gall bladder wall thickening, gall bladder distension, pericholecystic fluid/oedema, pericholecystic fat stranding, transient increased enhancement of adjacent liver parenchyma are often associated with acute cholecystitis and these findings can be well established from CT. CT is also useful for evaluating the many complications of acute cholecystitis, such as emphysematous cholecystitis, gangrenous cholecystitis, haemorrhage, and gall stone ileus.

HOW TO CITE THIS ARTICLE: Belman M, Toka M, Panditi S. Role of CT in the evaluation of acute cholecystitis. J. Evolution Med. Dent. Sci. 2019;8(21):1735-1740, DOI: 10.14260/jemds/2019/381

\section{BACKGROUND}

Acute cholecystitis is an acute inflammatory condition of the gall bladder; $95 \%$ of cases of acute cholecystitis are due to an obstructing calculus in the gall bladder neck or cystic duct. 1 The pathophysiology of acute cholecystitis is complex and not completely understood. In $96 \%$ of cases there are gallstones, and typically, a calculus causes cystic duct obstruction.2,3 The trapped concentrated bile has an irritative effect on the gallbladder wall, causing increased secretions leading to distention, wall edema, and hypervascularity of the wall. ${ }^{4}$ As intraluminal pressure rises, vessels become compressed that may result in thrombosis, ischemia, and subsequent necrosis of the gallbladder wall. Bacterial colonization, perforation, or abscess formation may also follow. Most (95\%) patients with acute cholecystitis have gallstones. As opposed to ultrasound, which is very sensitive and specific for the detection of gallstones, CT detects only approximately $75 \%$ of patients

'Financial or Other Competing Interest': None.

Submission 06-03-2019, Peer Review 10-05-2019,

Acceptance 17-05-2019, Published 27-05-2019.

Corresponding Author:

Dr. Murali Belman,

Plot No. 702 A, Road No. 36, Jubilee Hills,

Hyderabad-500033, Telangana, India.

E-mail: drbelmanmurali@gmail.com

DOI: $10.14260 /$ jemds/2019/381 with gallstones. ${ }^{5}$ With CT, gallstones have a varied appearance based on their composition and pattern of calcification. Stones with calcifications tend to be well seen with CT. However, stones with a high cholesterol content may be difficult to detect because they may be hypoattenuating or isoattenuating compared with bile. In patients younger than 50 years of age, women are affected by acute cholecystitis 3 times more frequently than men, reflecting the higher prevalence of gallstones in women. After 50 years of age, the distribution of acute cholecystitis between men and women is nearly equal. In $75 \%$ of cases, there is a history of biliary colic characterized by right upper quadrant pain, nausea, vomiting, or dyspepsia. Pain may radiate to the epigastrium, back, or shoulder. On physical examination, right upper quadrant tenderness and guarding are noted. Murphy's sign or point tenderness over the gallbladder's may be present. This sign was originally described as the arrest of inspiration when the right subcostal margin is palpated. Laboratory findings are nonspecific and include mild elevations of serum bilirubin, amylase, and transaminases. An elevated white blood cell count is usually present. 2,6

Acute acalculous cholecystitis (AAC) is defined as an acute necro-inflammatory disease of the gallbladder in the absence of cholelithiasis and has a multifactorial pathogenesis. 7,8 It accounts for approximately $10 \%$ of all cases of acute cholecystitis. AAC occurs in about $0.2 \%$ to 
$0.4 \%$ of all critically ill patients usually about 60 years of age, with an approximate male: female ratio of 2 to 3:1; and may occur from 1 to 50 days after an inciting event. 8-14

Clinically, AAC is indistinguishable from acute calculous cholecystitis.15,16 Many clinical findings occur but are nonspecific to AAC: right upper-quadrant pain, fever, leukocytosis, and abnormal liver tests (Aminotransferases, alkaline phosphatase, and bilirubin).7,8,13

There are several dreaded complications of AACgangrene, perforation, and empyema. These occur in $6 \%$ to $82 \%$ of cases, but most studies show about $40 \%$ occurrence. Attempts at predicting their occurrence have been unsuccessful till date. This is unfortunate because those with such complications more often face mortality.7,15-23

Mortality depends mostly on how critically ill the patient is at the time of diagnosing. A significant number of outpatients present with AAC, especially associated with diabetes, vascular disease, and hypertension, who unlike the inpatient usually have a very straightforward diagnosis and excellent prognosis with prompt cholecystectomy. ${ }^{14,22,24-27}$ The etiology of AAC is multifactorial and likely results from bile stasis or ischemia (Or both). Bile stasis can be caused by fasting, obstruction, postsurgical/procedural irritation or ileus (Total parenteral nutrition [TPN]), which can lead to bile inspissation that is directly toxic to the gallbladder Epithelium. ${ }^{18,28}$

Ischemia to the organ may occur from many of the risks associated with systemic inflammation and could have deleterious effects directly to all layers of the gallbladder (GB) wall.29-32

AAC showed the following

1. Increased leukocyte margination (Corresponding to ischemia and reperfusion injury) ${ }^{33}$

2. Increased focal lymphatic dilation with interstitial oedema associated with local microvascular occlusion (Ischemia related).

3. Increased and deeper bile infiltration in the GB wall of AAC suggesting that bile stasis and increased epithelial permeability exist, leading to epithelial damage. ${ }^{10}$

\section{Aims and Objectives}

The objective of this study is to assess the role of CT in the evaluation of acute cholecystitis and its complications. The study compares the CT findings of acute cholecystitis with clinical findings and helps in understanding the associated complications and extent of involvement before planning the management of acute cholecystitis.

\section{METHODS}

The study was a Cross Sectional study conducted at Baskar General Hospitals, Moinabad, Hyderabad for a period of 14 months between March 2016 and May 2017. All patients with clinical suspicion/Diagnosis of Acute cholecystitis referred for CT were consecutively inducted into the study after receiving informed consent. Imaging was performed on the Toshiba Alexion CT scan and sections from above the level of Diaphragm to Pubic symphysis. Plain study was first performed, and contrast was injected to get the arterial, venous and delayed phases as needed. Non-Ionic Contrast media (OMNIPAQUE 350) was used and the flow rate was adjusted to $4 \mathrm{ml} / \mathrm{s}$ by an injection pump for every $1.5 \mathrm{ml} / \mathrm{Kg}$ of body weight.

\section{Inclusion Criteria}

1. Patients with signs and symptoms of Acute cholecystitis that is who are presenting with Right upper quadrant pain and Positive Murphy's sign on clinical examination.

2. Patients with suspected Complicated Acute cholecystitis.

3. Patients with Inconclusive Ultrasound who needs CT as further imaging for confirmation of diagnosis.

\section{Exclusion Criteria}

1. With history of chronic kidney disease whose Serum creatinine values are more than $1.2 \mathrm{md} / \mathrm{dl}$.

2. Contrast medium was contraindicated like pregnant females and who are allergic to the contrast medium.

3. Patients who didn't give consent to participate in the study.

The images were analysed by the operator blinded to the clinical details and histopathological, surgical/ follow up details. The following observations were looked into:

- Presence or absence of calculus was noted. Most of the stones are cholesterol stones which are Radiolucent on CT. The site of the gall bladder calculus was also noted as the calculus impacted in the cystic duct or neck causes extrinsic compression over the adjacent CBD and resulting in Dilated CBD and IHBRD.

- Wall thickening was noted and considered significant if the wall thickness is more than $4 \mathrm{~mm}$. The Enhancement pattern of the gall bladder wall was also assessed weather there is Irregular and discontinuous enhancement.

- Distension of the Gall bladder was noted. It was further categorized into grossly distended (length is more than 8 cms and transverse diameter more than 4-5 cms)

- Pericholecystic Fluid and Oedema in the form of mural striations are noted. It can be assessed in the plain study also but better delineated on contrast study as the wall and the oedema can be clearly demarcated.

- Pericholecystic fat stranding was noted and assessed weather it is present or not. The fat stranding is seen in both Plain and contrast study.

- On contrast administration few cases of cholecystitis show transient increased hepatic attenuation around the gall bladder in arterial phase in curvilinear fashion. The presence or absence of the increased hepatic attenuation was assessed.

- $\quad$ The presence of any intramural defect or discontinuity in the gall bladder wall was noted and the site of the defect involving which wall of the gall bladder was also noted. A note is also made of presence of pericholecystic collection.

- A note made if any Intraluminal membranes are present.

- Presence of Intraluminal or Intramural air was noted.

- Other features like Ascites, Thickened Peritoneum with enhancement, dilated small bowel loops in case of obstruction due to passed off gall stone was noted. 

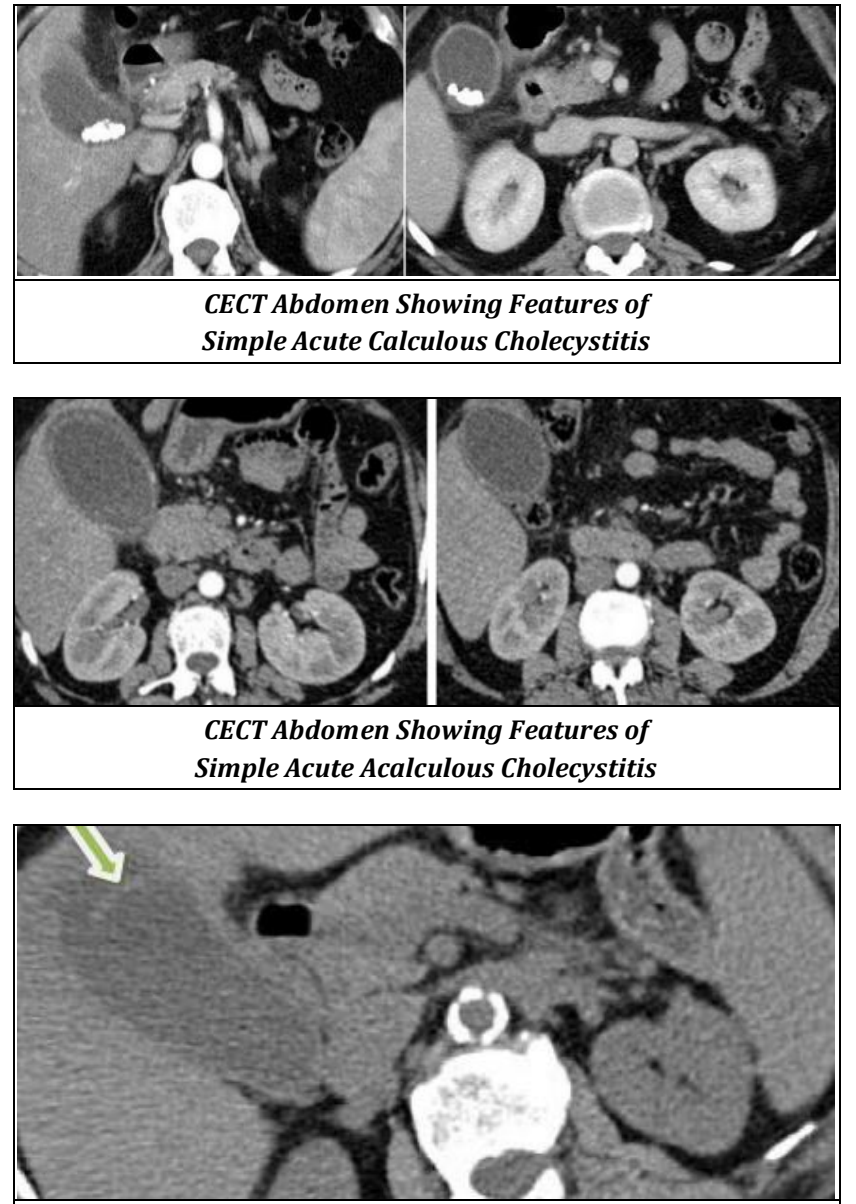

CT Abdomen-Gangrenous Cholecystitis with Irregular GB Mucosa and Hyperdense Intraluminal Membrane
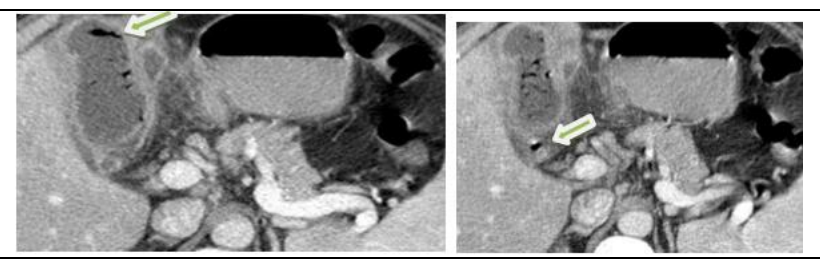

Emphysematous Cholecystitis A) and B) CECT Abdomen Showing Intramural and Intraluminal Air with Thickened and Enhancing Walls. Pericholecystic Fluid, Oedema and Fat Standing Seen

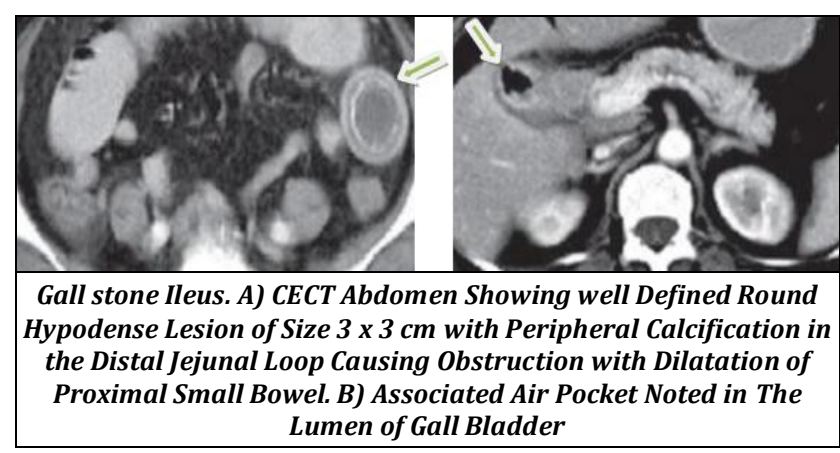

\section{RESULTS}

They study included fifty patients with acute cholecystitis. The average age of the group was $60.7 \pm 1.76$ (range from 3080) with a sex distribution in the group being 21:29 (M: F). The highest incidence was found in 61-70 years age group accounting for $32.0 \%$ of cases and least was seen in age group of $41-50$ years constituting $8 \%$.

\begin{tabular}{|c|c|c|}
\hline Sl. No. & Age Group & Number (\%) \\
\hline 1 & $31-40$ & $05(10 \%)$ \\
\hline 2 & $41-50$ & $04(8 \%)$ \\
\hline 3 & $51-60$ & $13(26 \%)$ \\
\hline 4 & $61-70$ & $16(32 \%)$ \\
\hline 5 & $71-80$ & $12(24 \%)$ \\
\hline \multicolumn{3}{|c|}{ Table 1. Age Distribution (N=70) } \\
\hline
\end{tabular}

\begin{tabular}{|c|c|c|}
\hline Sl. No. & Clinical Symptom & No of Patients (\%) \\
\hline 1 & Right upper quadrant (RUQ) pain & $42(84 \%)$ \\
\hline 2 & Vague abdominal discomfort & $08(16 \%)$ \\
\hline 3 & RUQ mass & $08(16 \%)$ \\
\hline 4 & Fever & $18(6 \%)$ \\
\hline 5 & Nausea & $16(32 \%)$ \\
\hline 6 & Vomiting & $15(30 \%)$ \\
\hline 7 & Dyspepsia & $14(28 \%)$ \\
\hline 8 & Jaundice & $11(22 \%)$ \\
\hline 9 & Abdominal distension & $1(2 \%)$ \\
\hline \multicolumn{2}{|c|}{ Table 2. Clinical Symptoms } \\
\hline
\end{tabular}

\begin{tabular}{|c|c|c|}
\hline Sl. No. & Description & No. of Patients (\%) \\
\hline 1 & Calculus & $42(84 \%)$ \\
\hline 2 & GB Wall thickening & $33(66 \%)$ \\
\hline 3 & GB distension & $32(64 \%)$ \\
\hline 4 & Pericholecystic fluid/oedema & $32(64 \%)$ \\
\hline 5 & Pericholecystic fat stranding & $42(84 \%)$ \\
\hline 6 & Transient adjacent liver parenchymal \\
enhancement & $21(42 \%)$ \\
\hline 7 & Intramural defects & $13(26 \%)$ \\
\hline 8 & Pericholecystic collection & $12(24 \%)$ \\
\hline 9 & Others & $11(22 \%)$ \\
\hline \multicolumn{3}{|c|}{ Table 3. Findings } \\
\hline
\end{tabular}

\begin{tabular}{|c|c|c|}
\hline Sl. No. & Description & No. of Patients \\
\hline 1 & Calculi & 23 \\
\hline 2 & GB Wall thickening $(>4 \mathrm{~mm})$ & 17 \\
\hline 3 & GB distension & 13 \\
\hline 4 & Pericholecystic fluid/oedema & 11 \\
\hline 5 & Pericholecystic fat stranding & 20 \\
\hline 6 & $\begin{array}{c}\text { Transient adjacent liver parenchymal } \\
\text { enhancement }\end{array}$ & 10 \\
\hline \multicolumn{2}{|c|}{ Table 4. Simple Acute Calculous Cholecystitis (23/50) } \\
\hline
\end{tabular}

\begin{tabular}{|c|c|c|}
\hline Sl. No. & Description & No of Patients \\
\hline 1 & Calculi & - \\
\hline 2 & GB Wall thickening $(>4 \mathrm{~mm})$ & 4 \\
\hline 3 & GB distension & 4 \\
\hline 4 & Pericholecystic fluid/oedema & 4 \\
\hline 5 & Pericholecystic fat stranding & 4 \\
\hline 6 & Transient adjacent liver parenchymal \\
enhancement & 2 \\
\hline \multicolumn{2}{|c|}{ Table 5. Acute Acalculous Cholecystitis (5/50) } \\
\hline
\end{tabular}

\begin{tabular}{|c|c|c|}
\hline Sl. No. & Description & No. of Patients \\
\hline 1 & Calculus & 1 \\
\hline 2 & GB Wall thickening $(>4 \mathrm{~mm})$ & 3 \\
\hline 3 & GB distension & 3 \\
\hline 4 & Pericholecystic fluid/oedema & 4 \\
\hline 5 & Pericholecystic fat stranding & 4 \\
\hline 6 & Transient adjacent liver parenchymal \\
enhancement & 2 \\
\hline \multicolumn{2}{|c|}{ Table 6. Gangrenous Cholecystitis (4/50) } \\
\hline
\end{tabular}

\begin{tabular}{|c|c|c|}
\hline Sl. No. & Description & No. of Patients (\%) \\
\hline 1 & Calculus & 11 \\
\hline 2 & GB Wall thickening $(>4 \mathrm{~mm})$ & 10 \\
\hline 3 & GB distension & 08 \\
\hline 4 & Pericholecystic fluid/oedema & - \\
\hline 5 & Pericholecystic fat stranding & 08 \\
\hline 6 & $\begin{array}{c}\text { Transient adjacent liver parenchymal } \\
\text { enhancement }\end{array}$ & 09 \\
\hline \multicolumn{3}{|c|}{ Table 7. GB Perforation with Pericholecystic Collection (12/50) } \\
\hline
\end{tabular}




\begin{tabular}{|c|c|c|}
\hline Sl. No. & Description & Findings \\
\hline 1 & Calculus & $\times$ \\
\hline 2 & GB Wall thickening (>4 mm) & $\checkmark$ \\
\hline 3 & GB distension & $\times$ \\
\hline 4 & Pericholecystic fluid/oedema & $\checkmark$ \\
\hline 5 & Pericholecystic fat stranding & $\checkmark$ \\
\hline 6 & $\begin{array}{c}\text { Transient adjacent liver parenchymal } \\
\text { enhancement }\end{array}$ & $\checkmark$ \\
\hline \multicolumn{2}{|c|}{ Table 8. GB Perforation with Gross Ascites and Peritonitis (1/50) } \\
\hline
\end{tabular}

\begin{tabular}{|c|c|c|}
\hline Sl. No. & Description & Findings \\
\hline 1 & Calculus & $\times$ \\
\hline 2 & GB Wall thickening (>4 mm) & $\checkmark$ \\
\hline 3 & GB distension & $\checkmark$ \\
\hline 4 & Pericholecystic fluid/oedema & $\times$ \\
\hline 5 & Pericholecystic fat stranding & $\checkmark$ \\
\hline 6 & Transient adjacent liver parenchymal \\
enhancement & $\checkmark$ \\
\hline \multicolumn{2}{|c|}{ Table 9. Emphysematous Cholecystitis (1/50) } \\
\hline
\end{tabular}

\begin{tabular}{|c|c|c|}
\hline Sl. No. & Description & No. of Patients \\
\hline 1 & Calculus & 2 \\
\hline 2 & GB Wall thickening (>4 mm) & 3 \\
\hline 3 & GB distension & 3 \\
\hline 4 & Pericholecystic fluid/oedema & 3 \\
\hline 5 & Pericholecystic fat stranding & 2 \\
\hline 6 & $\begin{array}{c}\text { Transient adjacent liver parenchymal } \\
\text { enhancement }\end{array}$ & 1 \\
\hline \multicolumn{3}{|c|}{ Table 10. ACC with Mirizzi's Syndrome (3/50) } \\
\hline
\end{tabular}

\begin{tabular}{|c|c|c|}
\hline Sl. No. & Description & Findings \\
\hline 1 & Calculus & $\checkmark$ \\
\hline 2 & GB Wall thickening (>4 mm) & $\checkmark$ \\
\hline 3 & GB distension & $\times$ \\
\hline 4 & Pericholecystic fluid/oedema & $\checkmark$ \\
\hline 5 & Pericholecystic fat stranding & $\checkmark$ \\
\hline 6 & Transient adjacent liver parenchymal enhancement & $\times$ \\
\hline \multicolumn{3}{|c|}{ Table 11. Gall Stone with Ileus (1/50) } \\
\hline
\end{tabular}

\section{DISCUSSION}

Table 2 shows the clinical symptoms of patients (Cumulative count) who were diagnosed with acute cholecystitis.

Right upper quadrant pain was the most common presenting complaint in $84.0 \%$ of cases. Fever $(36.0 \%)$, nausea (32\%), vomiting (30.0\%), Dyspepsia (28.0\%), Jaundice (22.0\%), Vague abdominal discomfort (16.0\%), Right upper quadrant mass $(16.0 \%)$, and Abdominal distension $(2.0 \%)$ were the other presenting complaints.

Table 3. Summarizes the findings from the evaluation of the 50 patients.

Of the fifty patients that were evaluated 42 of them (84.0\%) had calculi and 11 (22.0\%) had no calculi. Two of them show impacted calculi in the neck and one in the cystic duct causing extrinsic compression over the CBD causing dilated CBD and IHBRD. $33(66.0 \%)$ patients show wall thickness more than $4 \mathrm{~mm}$ and $17(34.0 \%)$ show less than 4 mm. $32(64.0 \%)$ cases showed grossly distended GB and 18 $(36.0 \%)$ cases show no gross distension of GB. Pericholecystic fluid/oedema was seen in 32 (64.0\%) cases whereas the rest $18(36.0 \%)$ cases showed no oedema. 42 $(84.0 \%)$ cases shows the presence of pericholecystic fat stranding. 21 cases (42.0\%) showed enhancement of the adjacent liver parenchyma while in 29 cases (58.0\%) no enhancement was detected. Intra mural defects in the GB wall were seen in 13 cases $(26.0 \%)$ rest of the $27(54.0 \%)$ cases show no defect. Most of the patients with GB wall perforation are associated with Pericholecystic collections. Out of fifty patients $12(24.0 \%)$ cases showed Pericholecystic collection, 1 case $(2.0 \%)$ showed gross ascites and rest of them 27 (54.0\%) showed no collection. The other predominant features like Intra luminal membranes are seen in $4(8.0 \%)$ cases, Irregular and discontinuous wall enhancement in $4(8.0 \%)$ cases, Intramural and luminal air in $1(2.0 \%)$ of case, Intraluminal air in $1(2.0 \%)$ case, Dilated small bowel loops with Obstruction features in $1(2.0 \%)$ case.

\section{Radiological Diagnosis with Case Examples}

Simple acute calculous cholecystitis.

Out of 50 patients evaluated, uncomplicated Acute calculous cholecystitis was seen in 23 (48\%) of cases with a sex distribution of 12:11 (M: F). All 23 cases show calculi, 17 Cases showed Wall thickening of more than $4 \mathrm{~mm}$. 13 Cases showed Gross GB Distension, 11 Cases showed Pericholecystic fluid/oedema, 20 Cases showed Pericholecystic fat stranding. Features of simple acute calculous cholecystitis in the study are similar to the study done by Fidler J et al. ${ }^{34} 10$ Cases showed Transient adjacent hepatic parenchymal enhancement. According to Yamashita $\mathrm{K}$ et al transient focal increased attenuation of the liver may occur on CT scans in patients with acute cholecystitis. The increased attenuation associated with acute cholecystitis has a typical location and pattern. This finding is probably attributable to hepatic arterial hyperemia and to early venous drainage caused by the adjacent inflamed gall bladder. 35

Out of the 50 patients, acute acalculous cholecystitis was found in $5(10.0 \%)$ cases with the sex distribution of 1:4 (M: F). All 5 cases had no demonstrable calculus, 4 cases had wall thickening, 4 cases had GB distension, 4 cases had pericholecystic fluid/oedema, 4 cases had fat stranding and 2 cases had transient adjacent liver parenchymal enhancement. Kalliafas S et al stated that AAC is a rare, but potentially lethal, disease occurring in critically ill patients and those recovering from non-biliary tract operations. The clinical presentation is nonspecific, and significant delays in diagnosis result in a high incidence of gangrene, perforation, abscess, and death. To improve outcome, a high index of suspicion with early radiographic evaluation, often employing multiple studies, is necessary. ${ }^{22}$

Of the 50 patients, 4 (8\%) cases were diagnosed as Gangrenous cholecystitis with a sex distribution of 3:1 (M: F). Calculus was seen in 1 case and absent in 3 cases. Wall thickening was seen in 3 cases. Grossly distended GB was seen 3 cases and pericholecystic fluid/oedema was seen in 4 cases. Pericholecystic fat stranding was seen in 4 cases. Transient adjacent hepatic parenchymal enhancement is seen in 2 cases, Irregular mucosal enhancement of the GB wall is seen in 4 cases, Intraluminal membranes was seen in 4 cases. Bennett GL et al stated that computed tomography findings most specific for acute gangrenous cholecystitis are gas in the wall or lumen, intraluminal membranes, irregular wall, and pericholecystic abscess. Gangrenous cholecystitis is associated with a lack of mural enhancement, pericholecystic fluid, and a greater degree of gallbladder distention and wall thickening. ${ }^{36}$ Chang WC et al stated that markedly distended gallbladder associated with decreased wall enhancement is highly specific for gangrenous cholecystitis. ${ }^{37} \mathrm{Wu} \mathrm{CH}$ et al stated that computed tomography was found to accurately diagnose acute cholecystitis, with the presence of perfusion defect, pericholecystic stranding, or no-gallstone condition significantly correlated with that of gangrenous change. 38 
Of the 50 patients, $12(24.0 \%)$ cases were those of GB Perforation with adjacent collection formation with a sex distribution of 8:4 (M: F). All were showing focal intramural defect with large adjacent collection. Out of the 12 cases, 11 showed calculi. 10 cases showed wall thickening more than 4 $\mathrm{mm}, 8$ cases showed grossly distended GB, 8 cases showed pericholecystic fat stranding and 9 cases showed adjacent liver parenchymal enhancement. Tsai MJ et al stated that computed tomography signs of gallbladder wall defect associated with acute cholecystitis may have high possibility of gallbladder rupture. 39

Of the 50 patients one male patient, aged 31 years showed the GB perforation with gross ascites and Biliary peritonitis. There was no evidence of calculus in this patient. The gall bladder wall thickening was more than $4 \mathrm{~mm}$, GB was not grossly distended in this case, Pericholecystic oedema, fat stranding and transient adjacent hepatic enhancement was seen in this case. Focal Intramural defect noted at fundus of GB wall. Other features of Gross ascites with thick and enhancing peritoneum was seen.

of the 50 patients, only one case presented with features of Emphysematous cholecystitis. The patient was 70 year old male. There was no calculus but the wall thickening was more than $4 \mathrm{~mm}$. Pericholecystic fat stranding and Grossly distended GB were seen. There was transient increased adjacent parenchymal enhancement. Intraluminal and intramural air pockets was seen.

Out of 50 patients 3 cases showed ACC with Mirizzi's syndrome with a sex distribution of 2:1 (M: F). Of these, two patients show Impacted calculus in the neck of gall bladder and one in the cystic duct causing extrinsic compression over CHD with IHBRD. All 3 of them showed wall thickening of more than $4 \mathrm{~mm}$ and also distended GB. 3 of them showed Pericholecystic fluid/oedema while 2 showed pericholecystic fat stranding. 1 case showed Transient adjacent liver parenchymal enhancement. Mathieu D et al stated that the Mirizzi's syndrome was diagnosed preoperatively on sonography in 2 out of 3 cases and on plain computed tomography scans in all 3 cases. ${ }^{40}$

Out of 50 patients, only one male individual was presented with Gall stone Ileus. The patient showed air with in the lumen of gall bladder and hypodense lesion with peripheral calcification noted in the distal loop of jejunum with dilated proximal small bowel loops which indicated passing of GB calculus that got impacted in the distal jejunum leading to features of small bowel obstruction. Wall thickening of more than $4 \mathrm{~mm}$ was seen, Pericholecystic fluid and fat stranding was also seen. No GB distension and increased adjacent liver parenchymal enhancement was seen. According to Lassandro $\mathrm{F}$ et al CT findings retrospectively observed were: bowel loops dilatation, airfluid levels, biliodigestive fistula, pneumobilia, ectopic stone and extraluminal fluid. The features of Intraluminal air in GB, small bowel obstruction and ectopic gall stone in this study was consistent with Lassandro $\mathrm{F}$ et al. ${ }^{41}$

Out of 50 patients, 44 patients had initial US done and then subsequently they were taken for CT study as the US was inconclusive, while rest 6 cases were directly sent for CT study who has strong clinical suspicion of complicated cholecystitis. Final diagnosis was established by-

- $\quad$ Surgical correlation (17 cases).

- Percutaneous cholecystostomy (14 cases).
- Telephonic conversations, treatment course and follow up imaging (19 cases).

\section{Limitations}

- Presence of Ionizing radiation and improper visualization of the iadiolucent calculi in CT for which Ultrasound is more appropriate for detection.

- The Positive Murphy's sign cannot be elucidated on CT as it is the most important diagnostic sign in acute cholecystitis.

- An important pitfall in the diagnosis of acute cholecystitis is lack of recognition of gallbladder wall oedema on CT. A relaxed (Non distended) gallbladder provides important evidence against the diagnosis of acute cholecystitis. Intensive care patients with sepsis often have no specific signs for diagnosis of acute cholecystitis, making diagnosis especially challenging.

- Normal GB wall thicknesses of $<3 \mathrm{~mm}$ at sonography and $\mathrm{CT}$, as confirmed pathologically, does not exclude $\mathrm{AAC}$ with gangrene or perforation, and underscores the possibility that focal or diffuse ischemic insults to the GB mucosa may be the primary aetiology of AAC.

\section{CONCLUSIONS}

CT is the imaging modality of choice for diagnosis of acute cholecystitis and its associated complications in emergency department setting due to its wide availability. Cholelithiasis, gall bladder wall thickening, gall bladder distension, pericholecystic fluid/oedema, pericholecystic fat stranding, transient increased enhancement of adjacent liver parenchyma are often associated with acute cholecystitis and these findings can be well established from CT. CT is also useful for evaluating the complications of acute cholecystitis, such as emphysematous cholecystitis, gangrenous cholecystitis, haemorrhage, and gallstone ileus. CT plays a critical role in patient management by suggesting the correct diagnosis based on characteristic imaging findings, identifying the complications especially in critically ill patients and reduce the morbidity and mortality by immediate percutaneous cholecystostomy or cholecystectomy.

\section{REFERENCES}

[1] Kimura Y, Takada T, Kawarada Y, et al. Definitions, pathophysiology and epidemiology of acute cholangitis and cholecystitis: Tokyo Guidelines. J Hepatobiliary Pancreat Surg 2007;14(1):15-26.

[2] Sharp KW. Acute cholecystitis. Surg Clin North Am 1988;68(2):269-79.

[3] Robins SL. Inflammation and repair. In: Robins SL, Coltran RS, Kumar V, eds. Pathologic basis of disease. $4^{\text {th }}$ edn. Philadelphia, PA: Saunders 1989: p. 40-3.

[4] Roch J, Grollan JH Jr, Steckel RJ. Arteriography in the diagnosis of gallbladder disease. Radiology 1969;92(7):1485-91.

[5] Memel DS, Balfe DM, Semelka RC. The biliary tract. In: Lee JKT, Sagel SS, Stanley RJ, et al. eds. Computed body tomography with MRI correlation. $3^{\text {rd }}$ edn. Vol. 2. Philadelphia, PA: Lippincott Raven 1998: p. 779803.

[6] Sherlock S, Dooley J. Gallstones and inflammatory gallbladder diseases. In: Malden MA, edr. Diseases of the liver and biliary system. Cambridge, MA: 
Blackwell Scientific 1997: p. 593-623.

[7] Barie PS, Eachempati SR. Acute acalculous cholecystitis. Curr Gastroenterol Rep 2003;5(4):3029.

[8] Owen CC, Jain R. Acute acalculous cholecystitis. Curr Treat Options Gastroenterol 2005;8(2):99-104.

[9] Laurila J, Laurila PA, Saarnio J, et al. Organ system dysfunction following open cholecystectomy for acute acalculous cholecystitis in critically ill patients. Acta Anaesthesiol Scand 2006;50(2):173-9.

[10] Laurila JJ, Ala-Kokko TI, Laurila PA, et al. Histopathology of acute acalculous cholecystitis in critically ill patients. Histopathology 2005;47(5):485-92.

[11] Beckman I, Dash N, Sefczek RJ, et al. Ultrasonographic findings in acute acalculous cholecystitis. Gastrointest Radiol 1985;10(4):387-9.

[12] Mariat G, Mahul P, Prev TN, et al. Contribution of ultrasonography and cholescintigraphy to the diagnosis of acute acalculous cholecystitis in intensive care unit patients. Intensive Care Med 2000;26(11):1658-63.

[13] Babb RR. Acute acalculous cholecystitis. A review. J Clin Gastroenterol 1992;15(3):238-41.

[14] Ryu JK, Ryu KH, Kim KH. Clinical features of acute acalculous cholecystitis. J Clin Gastroenterol 2003;36(2):166-9.

[15] Glenn F, Becker CG. Acute acalculous cholecystitis. An increasing entity. Ann Surg 1982;195(2):131-6.

[16] Glenn F. Acute acalculous cholecystitis. Ann Surg 1979;189(4):458-65.

[17] Inoue T, Mishima Y. Postoperative acute cholecystitis: a collective review of 494 cases in Japan. Jpn J Surg 1988;18(1):35-42.

[18] McChesney JA, Northup PG, Bickston SJ. Acute acalculous cholecystitis associated with systemic sepsis and visceral arterial hypoperfusion: a case series and review of pathophysiology. Dig Dis Sci 2003;48(10):1960-7.

[19] Iaria C, Arena L, Di Maio G, et al. Acute acalculous cholecystitis during the course of primary EpsteinBarr virus infection: a new case and a review of the literature. Int J Infect Dis 2008;12(4):391-5.

[20] Wang AJ, Wang TE, Lin CC, et al. Clinical predictors of severe gallbladder complications in acute acalculous cholecystitis. World J Gastroenterol 2003;9(12):2821-3.

[21] Helbich TH, Mallek R, Madl D, et al. Sonomorphology of the gallbladder in critically ill patients. Value of a scoring system and follow-up examinations. Acta Radiol 1997;38(1):129-34.

[22] Kalliafas S, Ziegler DW, Flancbaum L, et al. Acute acalculous cholecystitis: incidence, risk factors, diagnosis and outcome. Am Surg 1998;64(5):471-5.

[23] Deitch EA, Engel JM. Ultrasonic detection of acute cholecystitis with pericholecystic abscesses. Am Surg 1981;47(5):211-4.

[24] Krishnamurthy GT, Krishnamurthy S, Brown PH. Constancy and variability of gallbladder ejection fraction: impact on diagnosis and therapy. J Nucl Med 2004;45(11):1872-7.

[25] Westlake PJ, Hershfiled NB, Kelly JK, et al. Chronic right upper quadrant pain without gallstones: does
HIDA scan predict outcome after cholecystectomy? Am J Gastroenterol 1990;85(8):986-90.

[26] Yap L, Wycherley AG, Morphett AD, et al. Acalculous biliary pain: cholecystectomy alleviates symptoms in patients with abnormal cholescintigraphy. Gastroenterology 1991;101(3):786-93.

[27] Ziessman HA. Cholecystokinin cholescintigraphy: clinical indications and proper methodology. Radiol Clin North Am 2001;39(5):997-1006.

[28] Shuman WP, Rogers JV, Rudd TG, et al. Low sensitivity of sonography and cholescintigraphy in acalculous cholecystitis. AJR Am J Roentgenol 1984;142(3):531-4.

[29] Kaminski DL, Amir G, Deshpande YG, et al. Studies on the etiology of acute acalculous cholecystitis: the effect of lipopolysaccharide on human gallbladder mucosal cells. Prostaglandins 1994;47(4):319-30.

[30] Kaminski DL, Andrus CH, German D, et al. The role of prostanoids in the production of acute acalculous cholecystitis by platelet-activating factor. Ann Surg 1990;212(4):455-61.

[31] Kaminski DL, Feinstein WK, Deshpande YG. The production of experimental cholecystitis by endotoxin. Prostaglandins 1994;47(3):233-45.

[32] Becker CG, Dubin T, Glenn F. Induction of acute cholecystitis by activation of factor XII. J Exp Med 1980;151(1):81-90.

[33] Taoka H. Experimental study on the pathogenesis of acute acalculous cholecystitis, with special reference to the roles of microcirculatory disturbances, free radicals and membrane-bound phospholipase A2. Gastroenterol Jpn 1991;26(5):633-44.

[34] Fidler J, Paulson EK, Layfield L. CT evaluation of acute cholecystitis: findings and usefulness in diagnosis. AJR Am J Roentgenol 1996;166(5):1085-8.

[35] Yamashita K, Jin MJ, Hirose Y, et al. CT finding of transient focal increased attenuation of the liver adjacent to the gallbladder in acute cholecystitis. AJR Am J Roentgenol 1995;164(2):343-6.

[36] Bennett GL, Rusinek H, Lisi V, et al. CT findings in acute gangrenous cholecystitis. AJR Am J Roentgenol 2002;178(2):275-81.

[37] Chang WC, Sun Y, Wu EH, et al. CT Findings for detecting the presence of gangrenous ischemia in cholecystitis. AJR Am J Roentgenol 2016;207(2):3029.

[38] Wu CH, Chen CC, Wang CJ, et al. Discrimination of gangrenous from uncomplicated acute cholecystitis: accuracy of CT findings. Abdom Imaging 2011;36(2):174-8.

[39] Tsai MJ, Chen JD, Tiu CM, et al. Can acute cholecystitis with gallbladder perforation be detected preoperatively by computed tomography in ED? Correlation with clinical data and computed tomography features. Am J Emerg Med 2009;27(5):574-81.

[40] Mathieu D, Aziza G, Vilgrain V, et al. Ultrasonographic and x-ray computed tomographic aspects of Mirizzi's syndrome. Gastroenterol Clin Biol 1989;13(11):9059.

[41] Lassandro F, Gagliardi N, Scuderi M, et al. Gallstone ileus analysis of radiological findings in 27 patients. Eur J Radiol 2004;50(1):23-9. 